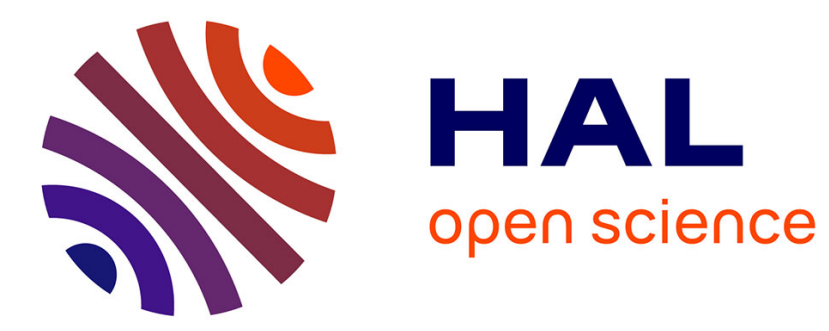

\title{
Technology Choice, Relative Performance Pay, and Worker Heterogeneity
}

Matthias Kräkel, Anja Schöttner

\section{To cite this version:}

Matthias Kräkel, Anja Schöttner. Technology Choice, Relative Performance Pay, and Worker Heterogeneity. Journal of Economic Behavior and Organization, 2010, 76 (3), pp.748. 10.1016/j.jebo.2010.08.016 . hal-00911828

\section{HAL Id: hal-00911828 \\ https://hal.science/hal-00911828}

Submitted on 30 Nov 2013

HAL is a multi-disciplinary open access archive for the deposit and dissemination of scientific research documents, whether they are published or not. The documents may come from teaching and research institutions in France or abroad, or from public or private research centers.
L'archive ouverte pluridisciplinaire HAL, est destinée au dépôt et à la diffusion de documents scientifiques de niveau recherche, publiés ou non, émanant des établissements d'enseignement et de recherche français ou étrangers, des laboratoires publics ou privés. 


\section{Accepted Manuscript}

Title: Technology Choice, Relative Performance Pay, and Worker Heterogeneity

Authors: Matthias Kräkel, Anja Schöttner

PII: $\quad$ S0167-2681(10)00169-1

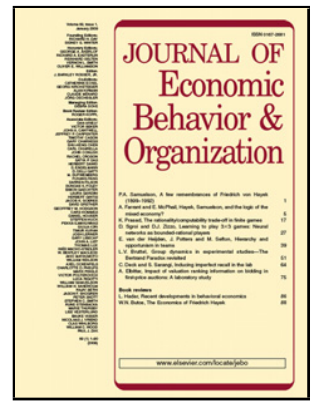

DOI: $\quad$ doi:10.1016/j.jebo.2010.08.016

Reference: $\quad$ JEBO 2596

To appear in: Journal of Economic Behavior \& Organization

Received date: $\quad 13-1-2010$

Revised date: $\quad 24-8-2010$

Accepted date: $\quad 24-8-2010$

Please cite this article as: Kräkel, M., Schöttner, A., Technology Choice, Relative Performance Pay, and Worker Heterogeneity, Journal of Economic Behavior and Organization (2010), doi:10.1016/j.jebo.2010.08.016

This is a PDF file of an unedited manuscript that has been accepted for publication. As a service to our customers we are providing this early version of the manuscript. The manuscript will undergo copyediting, typesetting, and review of the resulting proof before it is published in its final form. Please note that during the production process errors may be discovered which could affect the content, and all legal disclaimers that apply to the journal pertain. 


\title{
Technology Choice, Relative Performance Pay, and Worker Heterogeneity*
}

\author{
Matthias Kräkel $^{\dagger} \quad$ Anja Schöttner ${ }^{\ddagger}$
}

\begin{abstract}
We identify a new problem that may arise when heterogeneous workers are motivated by relative performance pay: If workers' abilities and the production technology are complements, the firm may prefer not to adopt a more advanced technology even though this technology would costlessly increase each worker's productivity. Due to the complementarity between ability and technology, under technology adoption the productivity of a more able worker increases more strongly than the productivity of a less able colleague. As a consequence, both workers' motivation to exert effort is reduced. We show that this adverse incentive effect is dominant and, consequently, keeps the firm from introducing a better production technology if talent uncertainty is sufficiently high and/or monitoring of workers is sufficiently precise.
\end{abstract}

Key Words: complementarities; heterogeneous workers; production technology; relative performance pay

JEL Classification: D82; D86; J33; M52.

\footnotetext{
${ }^{*}$ We thank two anonymous referees for valuable comments. Financial support by the Deutsche Forschungsgemeinschaft (DFG), grant SFB/TR 15, is gratefully acknowledged.

${ }^{\dagger}$ University of Bonn, Adenauerallee 24-42, D-53113 Bonn, Germany, tel: +49 228 733914, fax: +49 228 739210, e-mail: m.kraekel@uni-bonn.de.

${ }^{\ddagger}$ University of Bonn, Adenauerallee 24-42, D-53113 Bonn, Germany, tel: +49 228 739217, fax: +49 228 739210, e-mail: anja.schoettner@uni-bonn.de.
} 


\section{Introduction}

A fundamental incentive problem in organizations arises from the fact that a firm often has only coarse information on its workers' effort. In particular, performance signals are often only ordinal and/or unverifiable. In the first case, the firm only observes an ordinal ranking of worker performance. In the latter case, performance is observable by the firm but not by a third party. In such situations, incentive schemes like individual bonuses or piece rates are not feasible because they require individual performance signals or they are subject to potential employer opportunism. If worker performance is unverifiable, ex-post the firm can save labor costs by wrongly claiming that workers have performed poorly. Since workers anticipate such opportunistic behavior, incentives would be completely erased.

However, when only ordinal and/or unverifiable performance signals are available, the firm can still rely on relative incentive schemes that distribute a fixed amount of money among the workers according to their relative performance (Malcomson 1984, 1986). ${ }^{1}$ In practice, we can observe diverse variants of such incentive schemes, e.g., bonus pools (Kanemoto and MacLeod 1992; Rajan and Reichelstein 2006, 2009; Budde 2007), job-promotion tournaments (Baker et al. 1994, Treble et al. 2001), sales contests (Kalra and Shi 2001; Murphy et al. 2004; Lim et al. 2009), and forced-distribution systems (Murphy 1992; Thomas 2002). Under each variant, the firm commits to pay a certain collective amount of money to the workers. Such a commitment is credible because a third party can verify whether the entire amount has been paid out by the firm. Since the firm is forced to pay out the total amount of money, it has no incentive to misrepresent the workers' performance. This important self-commitment property assures worker incentives.

In this paper, we point out that the use of relative performance pay can be highly problematic if the firm can choose between different production

\footnotetext{
${ }^{1}$ Another well-known solution to the unverifiability problem are relational (or selfenforcing) contracts (see, e.g., Bull 1987; Baker et al. 2002). For a relational contract to be feasible, the firm's loss from reneging must be sufficiently large, e.g., the employeremployee relationship needs to be sustained with sufficiently high probability in the future and the associated future profit must not be discounted heavily.
} 
technologies. We characterize situations in which the firm foregoes to install a new technology although this technology would increase each worker's productivity and is costlessly available. When choosing the technology, the firm faces the following trade-off: On the one hand, a more advanced technology enhances each worker's productivity (productivity effect). On the other hand, if worker ability and firm technology are complements and workers differ in their abilities, the new technology increases the productivity of a more able worker more strongly than the productivity of a less able worker. Thus, the outcome of worker competition for bonus shares is less responsive to changes in effort and, consequently, both workers exert less effort (adverse incentive effect). If the adverse incentive effect dominates the productivity effect, the firm will not adopt the advanced technology.

In a next step, we use a parameterized example to highlight the impact of worker heterogeneity on technology choice. We show that, the higher the degree of worker heterogeneity and the higher the uncertainty about workers' ex-ante unknown talents, the more likely the firm is to choose the less productive technology. In particular, we compare two labor market situations that differ in the expected ability of the workers. We demonstrate that the firm may adopt the more advanced technology only in the situation with lower expected worker ability. Such a scenario occurs if talent uncertainty in the situation with higher average ability is sufficiently high compared to the situation with lower average ability. Furthermore, if workers' equilibrium efforts are rather small under either technology due to imprecise performance measurement or steep marginal effort costs, the adverse incentive effect of technology adoption is not severe. As a result, if the firm's monitoring technology is imprecise, the firm is more inclined to invest in a better production technology. Hence, if worker ability and production technology are complements in the firm's production function, monitoring technology and production technology are substitutes.

Theoretic contributions to moral hazard in principal-agent relationships typically consider either limited liability or risk aversion of workers as contractual frictions (e.g., Laffont and Martimort 2002, chapter 4). Until Section 4 , the paper focuses on the case where workers are risk neutral and protected 
by limited liability. To check the robustness of our findings, Section 5 turns to the case of risk averse workers. There, we analyze both the case of limitedly liable workers and of unlimited liability. Whereas limited liability of risk-averse workers leads to the same two opposite effects as the case of risk neutral workers - a positive productivity effect and an adverse incentive effect, switching to unlimited liability adds a third effect: If a better technology decreases effort due to more uneven worker competition, effort costs will be reduced as well. Under unlimited liability, this cost reduction directly benefits the firm, which can then lower expected wage payments since the workers' participation constraint can always be made binding. Hence, the firm is in favor of introducing the better technology under unlimited liability rather than under limited one.

The theoretical setting with ability and technology being complements fits well with the situation observed in the last decades where firms intensely invested in information technologies (IT). Initially, investment in IT was used to save labor and to substitute capital for low-ability work. However, nowadays IT and workers' abilities are mainly seen as complements (see, among many others, Applegate et al. 1988; Berndt et al. 1992; Hitt and Snir 1999; Bresnahan et al. 2002). IT is used by high-ability workers for improving time to market in research and development and improving service to key customers, for example. In other words, rather complex IT is used by firms for intensively exploiting the potential of their high-ability workers, hence making them more productive.

Besides the literature cited above, our paper is related to the work on rank-order tournaments starting with the seminal articles by Lazear and Rosen (1981), Green and Stokey (1983) and Nalebuff and Stiglitz (1983). Subsequent papers pointed to specific disadvantages of tournaments. Two major problems of tournaments have been emphasized in the literature. First, workers can improve their relative positions in the ranking by investing in counterproductive effort or sabotage (Lazear 1989; Konrad 2000; Chen 2003; Münster 2007; Amegashie and Runkel 2007; Gürtler 2008). Second, similar to cartels in market competition, tournament participants can collectively gain by a stable collusion that minimizes effort costs (Ishiguro 2004; Chen 2006; 
Sutter and Strassmair 2009). In this paper, we identify a further problem of bonus pools or tournaments - an adverse effect on technology choice given that worker ability and production technology are complements.

The remainder of the paper is organized as follows. In the next section, we introduce the model setup. Section 3 solves the workers' problem of effort choice under a given bonus-pool incentive scheme. Section 4 focuses on the firm's problems of designing the optimal bonus-pool contract and choosing the optimal production technology. Section 5 extends the analysis to the case of risk averse workers. Section 6 concludes.

\section{The Model}

We consider a firm that employs two workers. All parties are risk neutral. ${ }^{2}$ Workers are protected by limited liability so that all payments to them must be non-negative. Worker $i$ 's $(i=1,2)$ contribution to firm profit (or, for short, output) is $h\left(e_{i}, a_{i}, \tau\right)+\varepsilon_{i}+\eta$. Here, $e_{i} \geq 0$ denotes worker $i$ 's effort choice, $a_{i}$ is the worker's exogenously given ability, and $\tau$ characterizes the firm's production technology. The random variable $\varepsilon_{i}$ describes idiosyncratic noise with $\varepsilon_{1}$ and $\varepsilon_{2}$ being identically and independently distributed with density $f(\varepsilon)$ and cumulative distribution function (cdf) $F(\varepsilon)$. Hence, the density of the composed random variable $\varepsilon_{2}-\varepsilon_{1}$ is a symmetric convolution around zero. We denote this convolution by $g(\cdot)$ and the corresponding cdf by $G(\cdot)$ and assume that $g(\cdot)$ is single-peaked at zero and that $G(\cdot)$ is twice differentiable. The random variable $\eta$ measures common noise, which influences both workers in the same way (e.g., the economic situation of the firm). ${ }^{3}$ Neither effort $e_{i}$ nor a worker's contribution $h\left(e_{i}, a_{i}, \tau\right)+\varepsilon_{i}+\eta$ is observable by the firm. Instead, the firm observes a noisy and unverifiable

\footnotetext{
${ }^{2}$ We discuss the case of risk-averse workers in Section 5.

${ }^{3}$ A similar noise structure can be found in Lazear and Rosen (1981) and Green and Stokey (1983). The assumption of a unimodal distribution is also common in tournament models; see, e.g., Dixit (1987), Drago et al. (1996), Hvide (2002), or Chen (2003).
} 
binary signal $s$ with: ${ }^{4}$

$$
s=\left\{\begin{array}{cc}
s_{1} & \text { if } h\left(e_{1}, a_{1}, \tau\right)+\varepsilon_{1}+\eta>h\left(e_{2}, a_{2}, \tau\right)+\varepsilon_{2}+\eta \\
s_{2} & \text { otherwise }
\end{array}\right.
$$

According to (1) the firm has only access to ordinal information concerning worker performance. Signal realization $s=s_{i}$ indicates that worker $i$ has performed better than worker $j(i, j=1,2 ; i \neq j) .^{5}$

The technology parameter $\tau \in\left\{\tau_{L}, \tau_{H}\right\}$ is chosen by the firm. It can either use a more advanced technology $\tau=\tau_{H}$ or a less advanced one $\tau=\tau_{L}<\tau_{H}$. For simplicity, we assume that technology adoption is free. ${ }^{6}$ The function $h\left(e_{i}, a_{i}, \tau\right)$ is strictly increasing in effort, ability, and the technology parameter, i.e., $\frac{\partial h}{\partial e_{i}}, \frac{\partial h}{\partial a_{i}}, \frac{\partial h}{\partial \tau}>0$. In particular, this means that, holding effort constant, a better technology increases the output of each worker. Furthermore, output is concave in effort, i.e., $\frac{\partial^{2} h}{\partial e_{i}^{2}} \leq 0$. The marginal productivity of effort increases with a better technology, i.e., $\frac{\partial^{2} h}{\partial e_{i} \partial \tau} \geq 0$. However, we do not impose a restriction on the sign of $\frac{\partial^{2} h}{\partial a_{i} \partial \tau}$, implying that technology and ability can be substitutes or complements. In case of substitutes $\left(\frac{\partial^{2} h}{\partial a_{i} \partial \tau} \leq 0\right)$, the marginal productivity of ability decreases under the better technology. Put differently, productivity differences due to distinct abilities are evened out because the advanced technology increases the productivity of less able workers more strongly. For example, this happens if the new technology makes the production task easier for workers of lower ability, so that they

\footnotetext{
${ }^{4}$ Binary-signal models are often used in the literature on moral hazard; see, among many others, Demougin and Garvie (1991) and Demougin and Fluet (2001).

${ }^{5}$ The assumption of rather poor information (in particular, ordinal or unverifiable information) on worker performance is quite realistic for lower hierarchy levels. For example, several firms apply holistic work organization where missing occupational barriers make the collection of cardinal and verifiable information prohibitively costly or even impossible. Instead, firms rely on relative performance evaluation by workers' superiors. See Ichniowski et al. (1997) and Lindbeck and Snower (2000) on holistic organizations. Relative performance evaluation is also an integral part of the traditional personnel policy of Japanese firms; see, e.g., Endo (1994).

${ }^{6}$ In practice, technology adoption is typically costly, where the adoption of a more advanced production technology is more expensive to the firm. Thus, introducing costs for technology adoption would only reinforce our result that the firm may prefer the less productive technology.
} 
can keep up with more capable colleagues. Such a situation might occur if the firm adopts an easier-to-handle computer operation system, like switching from MS-DOS to MS-Windows. By contrast, if technology and ability are complements $\left(\frac{\partial^{2} h}{\partial a_{i} \partial \tau}>0\right)$, more able types benefit more from the advanced technology, e.g., if the new technology is complex and difficult to handle (as replacing typewriters with personal computers). Finally, to simplify the analysis, we assume that the marginal productivity of effort does not interact with ability, i.e., $\frac{\partial^{2} h}{\partial e_{i} \partial a_{i}}=0 .^{7}$

A worker's ability can be either high or low, $a_{i} \in\left\{a_{L}, a_{H}\right\}$, where $a_{H}>$ $a_{L} \geq 0$. The probability that a worker is of high ability is denoted by $p \in(0,1)$ and is common knowledge. After accepting the contract offered by the firm and entering into the employment relationship, each worker becomes familiar with the task to be conducted in this particular firm, and can thus assess how good he will be at it. Consequently, every worker learns his own ability. Moreover, each worker also observes the type of his colleague, whereas the firm never observes workers' abilities. This assumption captures the fact that employees who work closely together usually possess better information about one another's talents than the firm. For simplicity, an agent's reservation utility is zero.

Worker $i$ 's costs of effort are $c\left(e_{i}\right)$ with $c^{\prime}\left(e_{i}\right), c^{\prime \prime}\left(e_{i}\right)>0$ for all $e_{i}>$ 0 and $c(0)=0$. To guarantee interior solutions, we further impose the restriction that $\frac{\partial h}{\partial e_{i}}\left(0, a_{i}, \tau\right)>c^{\prime}(0)$. The relative performance signal (1) renders individual pay-for-performance schemes infeasible, but the firm can employ a relative incentive scheme such as a fixed bonus pool $B \geq 0$ to provide its workers with effort incentives. In order to induce appropriate incentives, the firm announces to pay $\alpha \cdot B$ to the better performing worker

\footnotetext{
${ }^{7}$ The assumption $\frac{\partial^{2} h}{\partial e_{i} \partial a_{i}}=0$ implies that we focus on the analysis of "unfair contests" in the sense of O'Keeffe et al. (1984) and Schotter and Weigelt (1992), who differentiate between "unfair" and "uneven" contests as two alternative ways of modeling heterogeneous players. In unfair contests, players exerting the same effort level have different winning probabilities. Technically, effort and ability enter the production function additively, leading to symmetric equilibria. However, in uneven contests effort and ability are multiplicatively connected (either in the production or the cost function), thus yielding asymmetric equilibria. Kräkel and Schöttner (2010) show that the main results derived in the present paper also extend to uneven contests.
} 
and $(1-\alpha) \cdot B$ to his co-worker. Limited liability requires that $0 \leq \alpha \leq 1$.

Timing is as follows. At the first stage, the firm makes the technological choice $\tau \in\left\{\tau_{L}, \tau_{H}\right\}$, which is publicly observable. Thereafter, it offers two randomly chosen workers a bonus-pool contract $(B, \alpha)$ specifying size and distribution of the bonus pool. ${ }^{8}$ Given that workers accept, they enter the firm and observe abilities. In stage 3, workers simultaneously choose their effort levels. Then, outputs and the signal (1) are realized. Finally, based on the realization of $s$, the firm shares $B$ between the workers according to the prespecified sharing rule $\alpha$.

\section{Workers' Effort Choices}

In this section, we derive workers' equilibrium effort levels given the firm's technological choice and the bonus-pool contract $(B, \alpha)$. These equilibrium efforts characterize the incentive constraints for the firm's optimization problem at the contracting stage 2 . When workers choose effort, they know the technology parameter $\tau$. Thus, given the effort choice $e_{2}$ of worker 2 , worker 1 chooses effort $e_{1}$ to maximize

$$
\begin{aligned}
& (1-\alpha) \cdot B \cdot\left[1-\operatorname{prob}\left\{h\left(e_{1}, a_{1}, \tau\right)+\varepsilon_{1}+\eta>h\left(e_{2}, a_{2}, \tau\right)+\varepsilon_{2}+\eta\right\}\right] \\
& +\alpha \cdot B \cdot \operatorname{prob}\left\{h\left(e_{1}, a_{1}, \tau\right)+\varepsilon_{1}+\eta>h\left(e_{2}, a_{2}, \tau\right)+\varepsilon_{2}+\eta\right\}-c\left(e_{1}\right) \\
& =(1-\alpha) B+(2 \alpha-1) B \cdot G\left(h\left(e_{1}, a_{1}, \tau\right)-h\left(e_{2}, a_{2}, \tau\right)\right)-c\left(e_{1}\right) .
\end{aligned}
$$

Similarly, worker 2 solves

$$
\max _{e_{2}}(1-\alpha) B+(2 \alpha-1) B \cdot\left[1-G\left(h\left(e_{1}, a_{1}, \tau\right)-h\left(e_{2}, a_{2}, \tau\right)\right)\right]-c\left(e_{2}\right) .
$$

We assume that the functional forms are such that worker $i$ 's objective function is concave in $e_{i}$ for all $e_{j}(i, j=1,2 ; i \neq j){ }^{9}$ Thus, the equilibrium effort

\footnotetext{
${ }^{8}$ Supplementing the bonus-pool contract, the firm could also offer a fixed payment to each worker. However, we do not consider this possibility because it does not lead to a superior contract from the firm's point of view.

${ }^{9}$ As already noted by Lazear and Rosen (1981, see p. 845, fn. 2) agents' objective functions are not necessarily concave under a relative performance scheme. In our model,
} 
levels $\left(e_{1}^{*}, e_{2}^{*}\right)$ are characterized by the two first-order conditions

$$
\begin{aligned}
& g\left(h\left(e_{1}^{*}, a_{1}, \tau\right)-h\left(e_{2}^{*}, a_{2}, \tau\right)\right) \cdot \frac{\partial h}{\partial e_{1}}\left(e_{1}^{*}, \tau\right) \cdot(2 \alpha-1) B-c^{\prime}\left(e_{1}^{*}\right)=0, \\
& g\left(h\left(e_{1}^{*}, a_{1}, \tau\right)-h\left(e_{2}^{*}, a_{2}, \tau\right)\right) \cdot \frac{\partial h}{\partial e_{2}}\left(e_{2}^{*}, \tau\right) \cdot(2 \alpha-1) B-c^{\prime}\left(e_{2}^{*}\right)=0 .
\end{aligned}
$$

Note that $\frac{\partial h}{\partial e_{i}}$ is independent of $a_{i}$ because of our assumption $\frac{\partial^{2} h}{\partial e_{i} \partial a_{i}}=0$. From the first-order conditions it follows that $c^{\prime}\left(e_{1}^{*}\right) / \frac{\partial h}{\partial e_{1}}\left(e_{1}^{*}, \tau\right)=c^{\prime}\left(e_{2}^{*}\right) / \frac{\partial h}{\partial e_{2}}\left(e_{2}^{*}, \tau\right)$. Thus, since $c^{\prime}\left(e_{i}\right) / \frac{\partial h}{\partial e_{i}}$ is strictly increasing in $e_{i}$, the equilibrium is unique and symmetric, $e_{1}^{*}=e_{2}^{*}=: e^{*}$. Hence, equilibrium effort $e^{*}\left(a_{1}, a_{2}, B, \alpha, \tau\right)$ is implicitly given by

$$
g\left(h\left(e^{*}, a_{1}, \tau\right)-h\left(e^{*}, a_{2}, \tau\right)\right) \cdot \frac{\partial h}{\partial e_{1}}\left(e^{*}, \tau\right) \cdot(2 \alpha-1) B-c^{\prime}\left(e^{*}\right)=0 .
$$

Implicit differentiation of equation (4) leads to our first proposition.

Proposition 1 If $a_{1} \neq a_{2}$ and $\frac{\partial^{2} h}{\partial a_{i} \partial \tau}>0$, then $e^{*}\left(a_{1}, a_{2}, B, \alpha, \tau\right)$ can be decreasing in the technology parameter $\tau$. In particular, $\frac{d e^{*}}{d \tau}<0$ if $\frac{\partial^{2} h}{\partial e_{i} \partial \tau}=0$.

Proof. Let $a_{1} \neq a_{2} \cdot{ }^{10}$ Applying the implicit function theorem to (4) gives

$$
\begin{gathered}
\operatorname{sign}\left(\frac{d e^{*}}{d \tau}\right)= \\
\operatorname{sign}\left(g^{\prime}\left(h\left(e^{*}, a_{1}, \tau\right)-h\left(e^{*}, a_{2}, \tau\right)\right)\left[\frac{\partial h}{\partial \tau}\left(e^{*}, a_{1}, \tau\right)-\frac{\partial h}{\partial \tau}\left(e^{*}, a_{2}, \tau\right)\right] \frac{\partial h}{\partial e_{1}}\left(e^{*}, \tau\right)\right. \\
\left.+g\left(h\left(e^{*}, a_{1}, \tau\right)-h\left(e^{*}, a_{2}, \tau\right)\right) \frac{\partial^{2} h}{\partial e_{1} \partial \tau}\left(e^{*}, \tau\right)\right) .
\end{gathered}
$$

Because $\frac{\partial^{2} h}{\partial e_{1} \partial \tau}\left(e^{*}, \tau\right) \geq 0$, the second term on the right-hand side of $(5)$ is nonnegative. Thus, we can obtain $\frac{d e^{*}}{d \tau}<0$ only if the first term on the right-hand strict concavity is ensured if $\left[g^{\prime}\left(h\left(e_{i}, a_{i}, \tau\right)-h\left(e_{j}, a_{j}, \tau\right)\right) \cdot\left(\frac{\partial h}{\partial e_{i}}\left(e_{i}, \tau\right)\right)^{2}+g\left(h\left(e_{i}, a_{i}, \tau\right)-\right.\right.$ $\left.\left.h\left(e_{j}, a_{j}, \tau\right)\right) \cdot \frac{\partial^{2} h}{\partial e_{i}^{2}}\left(e_{i}, \tau\right)\right] \cdot(2 \alpha-1) B-c^{\prime \prime}\left(e_{i}\right)<0$ for all $e_{i}, e_{j}, a_{i}, a_{j}$. This condition is satisfied if the density $g(\cdot)$ is sufficiently flat (i.e., the variance of $\varepsilon_{2}-\varepsilon_{1}$ is sufficiently large) and/or $c(\cdot)$ is sufficiently convex.

${ }^{10}$ For $a_{1}=a_{2}$, equation (4) boils down to $g(0) \cdot \frac{\partial h}{\partial e_{1}}\left(e^{*}, \tau\right) \cdot(2 \alpha-1) B-c^{\prime}\left(e^{*}\right)=0$. Here, $d e^{*} / d \tau \geq 0$ due to $\frac{\partial^{2} h}{\partial e_{1} \partial \tau}\left(e^{*}, \tau\right) \geq 0$. 
side is negative. This is the case if and only if $\frac{\partial^{2} h}{\partial a_{i} \partial \tau}>0$ : Then, we either have $g^{\prime}\left(h\left(e^{*}, a_{1}, \tau\right)-h\left(e^{*}, a_{2}, \tau\right)\right)<0$ and $\frac{\partial h}{\partial \tau}\left(e^{*}, a_{1}, \tau\right)-\frac{\partial h}{\partial \tau}\left(e^{*}, a_{2}, \tau\right)>0$ (if $\left.a_{1}>a_{2}\right)$ or $g^{\prime}\left(h\left(e^{*}, a_{1}, \tau\right)-h\left(e^{*}, a_{2}, \tau\right)\right)>0$ and $\frac{\partial h}{\partial \tau}\left(e^{*}, a_{1}, \tau\right)-\frac{\partial h}{\partial \tau}\left(e^{*}, a_{2}, \tau\right)<0$ (if $a_{1}<a_{2}$ ) because $\frac{\partial h}{\partial a_{i}}>0$ and $g(\cdot)$ is single-peaked at zero.

Proposition 1 shows that, if ability and technology are complements and workers are heterogeneous, adopting an enhanced production technology may have an adverse effect on effort, i.e., decrease workers' equilibrium effort choices. This is the case whenever the counteracting positive effect on the marginal productivity of effort, $\frac{\partial^{2} h}{\partial e_{i} \partial \tau}$, is not too strong and, in particular, if such an effect does not exist, $\frac{\partial^{2} h}{\partial e_{i} \partial \tau}=0$. The intuition for this finding can be best seen by inspection of (4): Since $g(\cdot)$ is single-peaked at zero, equilibrium efforts will be lower the higher $\left|h\left(e^{*}, a_{1}, \tau\right)-h\left(e^{*}, a_{2}, \tau\right)\right|$. As technology and ability are complements, a better technology makes an initially asymmetric competition with $a_{1} \neq a_{2}$ even more asymmetric (i.e., $\left|h\left(e^{*}, a_{1}, \tau\right)-h\left(e^{*}, a_{2}, \tau\right)\right|$ increases $)$, which further weakens both workers' incentives. By contrast, if ability and technology are substitutes or workers are homogeneous, equilibrium effort always increases with a superior technology.

\section{The Firm's Decisions}

We now consider the stage where the firm decides on the optimal bonus-pool contract $(B, \alpha)$, given the technology parameter $\tau$. Let $P_{H}:=p^{2}\left(P_{L}:=\right.$ $\left.(1-p)^{2}\right)$ denote the probability of a homogeneous match with two highability (low-ability) workers and $P_{H L}:=p(1-p)$ the probability of a heterogeneous match. Anticipating workers' equilibrium behavior $e^{*}\left(a_{1}, a_{2}, B, \alpha, \tau\right)$ as incentive constraint, the firm chooses $B$ and $\alpha$ in order to maximize expected output net of wage costs, i.e.,

$$
\begin{gathered}
P_{H} \cdot 2 h\left(e^{*}\left(a_{H}, a_{H}, B, \alpha, \tau\right), a_{H}, \tau\right)+P_{L} \cdot 2 h\left(e^{*}\left(a_{L}, a_{L}, B, \alpha, \tau\right), a_{L}, \tau\right) \\
+2 P_{H L} \cdot\left[h\left(e^{*}\left(a_{H}, a_{L}, B, \alpha, \tau\right), a_{H}, \tau\right)+h\left(e^{*}\left(a_{H}, a_{L}, B, \alpha, \tau\right), a_{L}, \tau\right)\right] \\
+2 E[\varepsilon]+2 E[\eta]-B .
\end{gathered}
$$


Thereby, the firm has to take into account the limited liability constraint $\alpha \in[0,1]$ and the workers' participation constraints. Recall that, before signing the contract, both workers are identical because they are characterized by symmetric ability uncertainty at this point. Thus, using that $1-G(x)=G(-x)$ by symmetry of $g(x)$, each worker faces the same participation constraint

$$
\begin{gathered}
E\left\{(2 \alpha-1) B\left[G\left(h\left(e^{*}\left(a_{1}, a_{2}, B, \alpha, \tau\right), a_{1}, \tau\right)-h\left(e^{*}\left(a_{1}, a_{2}, B, \alpha, \tau\right), a_{2}, \tau\right)\right)\right]\right. \\
\left.+(1-\alpha) B-c\left(e^{*}\left(a_{1}, a_{2}, B, \alpha, \tau\right)\right)\right\} \geq 0 .
\end{gathered}
$$

Here, the expectation operator refers to the different possible realizations of the abilities $a_{1}$ and $a_{2}$.

In order to solve the firm's problem, first note that we can ignore the participation constraint: Under any ability match, each worker can ensure himself a non-negative expected utility and, hence, his reservation value, by entering the competition for bonus shares and choosing zero effort. Thus, it is rational for him to accept any feasible bonus-pool contract with nonnegative $B$ and $0 \leq \alpha \leq 1$. Moreover, the firm optimally chooses $\alpha=1$ to maximize workers' effort for any given bonus pool $B$ (see (4)). Therefore, we now define $e^{*}\left(a_{1}, a_{2}, B, \tau\right):=e^{*}\left(a_{1}, a_{2}, B, 1, \tau\right)$. The following proposition summarizes our findings for the optimal bonus-pool contract: ${ }^{11}$

Proposition 2 The firm chooses the bonus-pool contract $(B, \alpha)=\left(B^{*}(\tau), 1\right)$ with

$$
\begin{gathered}
B^{*}(\tau)=\arg \max _{B \geq 0} P_{H} 2 h\left(e^{*}\left(a_{H}, a_{H}, B, \tau\right), a_{H}, \tau\right)+P_{L} 2 h\left(e^{*}\left(a_{L}, a_{L}, B, \tau\right), a_{L}, \tau\right) \\
\quad+2 P_{H L}\left[h\left(e^{*}\left(a_{H}, a_{L}, B, \tau\right), a_{H}, \tau\right)+h\left(e^{*}\left(a_{H}, a_{L}, B, \tau\right), a_{L}, \tau\right)\right]-B
\end{gathered}
$$

The proposition shows that the optimal bonus-pool contract is a winner-

\footnotetext{
${ }^{11}$ For brevity we skip $2 E[\varepsilon]+2 E[\eta]$ in the firm's objective function. Furthermore, we assume that the functional forms are such that the firm's objective function is strictly concave in $B$. For example, this is the case if (i) $h\left(e_{i}, a_{i}, \tau\right)$ is linear in $e_{i}$ and (ii) $c^{\prime \prime \prime}>0$. Then, by (i), $g\left(h\left(e^{*}, a_{1}, \tau\right)-h\left(e^{*}, a_{2}, \tau\right)\right) \cdot \frac{\partial h}{\partial e_{1}}\left(e^{*}, \tau\right)$ is independent of $e^{*}$. Thus, from (ii) and (4) it follows that $e^{*}$ is strictly concave in $B$. Consequently, $h\left(e^{*}, a_{i}, \tau\right)$ is also strictly concave in $B$ because $h\left(e_{i}, a_{i}, \tau\right)$ is increasing and strictly concave in $e_{i}$.
} 
takes-all contest with the best performing worker obtaining the entire bonus pool. The optimal size of this bonus pool trades off marginal incentives via implemented efforts $e^{*}\left(a_{1}, a_{2}, B^{*}(\tau), \tau\right)$ and marginal labor costs. ${ }^{12}$

Now we turn to the first stage, where the firm chooses the production technology $\tau \in\left\{\tau_{L}, \tau_{H}\right\}$. The firm's profit under the optimal bonus-pool contract with pool size $B^{*}=B^{*}(\tau)$ is given by

$$
\begin{gathered}
\pi\left(B^{*}(\tau), \tau\right)=P_{H} 2 h\left(e^{*}\left(a_{H}, a_{H}, B^{*}, \tau\right), a_{H}, \tau\right)+P_{L} 2 h\left(e^{*}\left(a_{L}, a_{L}, B^{*}, \tau\right), a_{L}, \tau\right)+ \\
2 P_{H L}\left[h\left(e^{*}\left(a_{H}, a_{L}, B^{*}, \tau\right), a_{H}, \tau\right)+h\left(e^{*}\left(a_{H}, a_{L}, B^{*}, \tau\right), a_{L}, \tau\right)\right]-B^{*}(\tau) .
\end{gathered}
$$

Although the firm faces a binary decision problem, differentiation of the objective function with respect to $\tau$ is helpful for deriving our results on the optimal technology choice. Applying the envelope theorem, the impact of technology on firm profit is given by

$$
\begin{aligned}
\frac{\partial \pi\left(B^{*}(\tau), \tau\right)}{\partial \tau}=2 P_{H} & \left\{\frac{\partial h}{\partial e}\left(e^{*}\left(a_{H}, a_{H}, B^{*}, \tau\right), a_{H}, \tau\right) \frac{\partial e^{*}}{\partial \tau}\left(a_{H}, a_{H}, B^{*}, \tau\right)+\right. \\
& \left.\frac{\partial h}{\partial \tau}\left(e^{*}\left(a_{H}, a_{H}, B^{*}, \tau\right), a_{H}, \tau\right)\right\}+ \\
2 P_{L} & \left\{\frac{\partial h}{\partial e}\left(e^{*}\left(a_{L}, a_{L}, B^{*}, \tau\right), a_{L}, \tau\right) \frac{\partial e^{*}}{\partial \tau}\left(a_{L}, a_{L}, B^{*}, \tau\right)+\quad(7)\right. \\
& \left.\frac{\partial h}{\partial \tau}\left(e^{*}\left(a_{L}, a_{L}, B^{*}, \tau\right), a_{L}, \tau\right)\right\}+ \\
2 P_{H L} & \left\{\left[\frac{\partial h}{\partial e}\left(e^{*}\left(a_{H}, a_{L}, B^{*}, \tau\right), a_{H}, \tau\right)+\right.\right. \\
& \left.\frac{\partial h}{\partial e}\left(e^{*}\left(a_{H}, a_{L}, B^{*}, \tau\right), a_{L}, \tau\right)\right] \cdot \frac{\partial e^{*}}{\partial \tau}\left(a_{H}, a_{L}, B^{*}, \tau\right)+ \\
& \left.\frac{\partial h}{\partial \tau}\left(e^{*}\left(a_{H}, a_{L}, B^{*}, \tau\right), a_{H}, \tau\right)+\frac{\partial h}{\partial \tau}\left(e^{*}\left(a_{H}, a_{L}, B^{*}, \tau\right), a_{L}, \tau\right)\right\} .
\end{aligned}
$$

The partial derivatives of $h$ with respect to $\tau$ reflect the direct effect of a marginal technology improvement on output for a given worker match. This effect is always positive by the assumption that $\frac{\partial h}{\partial \tau}>0$. The remaining

\footnotetext{
${ }^{12}$ Our finding is similar to Proposition 3 in Budde (2007). However, Budde considers homogeneous workers and allows for more than two contestants.
} 
terms characterize the impact of an enhanced technology on workers' effort choices and, consequently, output. By the proof of Proposition 1, in the two homogeneous matches where workers are either both of low or both of high ability, equilibrium effort is increasing in the technology parameter $\tau$, i.e., $\frac{\partial e^{*}}{\partial \tau}\left(a_{k}, a_{k}, B^{*}, \tau\right) \geq 0$ for $k=L, H$. However, if workers are heterogeneous, equilibrium effort may be decreasing, i.e., $\frac{\partial e^{*}}{\partial \tau}\left(a_{H}, a_{L}, B^{*}, \tau\right)<0$ is possible. As outlined in the discussion of Proposition 1, $\frac{\partial e^{*}}{\partial \tau}\left(a_{H}, a_{L}, B^{*}, \tau\right)<0$ particularly holds if technology and ability are complements and effort and technology are independent. In such a situation, a better technology $\tau_{H}>\tau_{L}$ exacerbates the problem of asymmetric worker competition and leads to a negative incentive effect. If this negative incentive effect dominates the direct positive impact of technology on output for all $\tau \in\left[\tau_{L}, \tau_{H}\right]$, then the firm will optimally choose the less productive technology $\tau_{L}$. By contrast, if the probability of a heterogeneous worker match is rather low, then the adverse incentive effect will not be decisive for the firm's adoption decision. Formally, from (7) we obtain that $\frac{\partial \pi\left(B^{*}(\tau), \tau\right)}{\partial \tau} \geq 0$ for all $\tau$ if $p$ approaches either 0 or 1 .

The following proposition summarizes our findings:

Proposition 3 If, for all $\tau \in\left[\tau_{L}, \tau_{H}\right]$,

$$
\begin{aligned}
& \sum_{i \in\{H, L\}} P_{i}\left\{\frac{\partial h}{\partial e}\left(e^{*}\left(a_{i}, a_{i}, B^{*}, \tau\right), a_{i}, \tau\right) \frac{\partial e^{*}}{\partial \tau}\left(a_{i}, a_{i}, B^{*}, \tau\right)+\frac{\partial h}{\partial \tau}\left(e^{*}\left(a_{i}, a_{i}, B^{*}, \tau\right), a_{i}, \tau\right)\right\}< \\
& -P_{H L} \sum_{i \in\{H, L\}}\left\{\frac{\partial h}{\partial e}\left(e^{*}\left(a_{H}, a_{L}, B^{*}, \tau\right), a_{i}, \tau\right) \frac{\partial e^{*}}{\partial \tau}\left(a_{H}, a_{L}, B^{*}, \tau\right)+\frac{\partial h}{\partial \tau}\left(e^{*}\left(a_{H}, a_{L}, B^{*}, \tau\right), a_{i}, \tau\right)\right\}
\end{aligned}
$$

then the firm will prefer technology $\tau_{L}$ to $\tau_{H}$. However, if $p$ approaches either 0 or 1 , the firm prefers $\tau_{H}$ to $\tau_{L}$.

We now present an example where the firm indeed prefers the inferior technology. Furthermore, the example allows to identify further determinants that prevent the adoption of a superior technology. We assume that the production function is

$$
h\left(e_{i}, a_{i}, \tau\right)=e_{i}+a_{i} \tau .
$$

Thus, effort and technology are independent while ability and technology 
are complements. ${ }^{13}$ Furthermore, let $\varepsilon_{2}-\varepsilon_{1}$ be normally distributed with $\varepsilon_{2}-\varepsilon_{1} \sim N\left(0, \sigma^{2}\right)$ and effort costs be given by the exponential function $c\left(e_{i}\right)=\exp \left(c e_{i}\right)-1$ with $c>0 .{ }^{14}$

At the effort stage, each worker's equilibrium strategy, as given by (4), can now be written as

$$
\begin{gathered}
g\left(\left(a_{1}-a_{2}\right) \tau\right)(2 \alpha-1) B=c \exp \left(c e^{*}\right) \\
\Leftrightarrow e^{*}=\frac{1}{c}\left[\ln \left(\frac{(2 \alpha-1) B}{c \sigma \sqrt{2 \pi}}\right)-\frac{\left(a_{1}-a_{2}\right)^{2} \tau^{2}}{2 \sigma^{2}}\right] .
\end{gathered}
$$

Obviously, $e^{*}$ decreases in $\left|a_{1}-a_{2}\right|$, as Proposition 1 predicts for the specific production function (8). Moreover, if $a_{1} \neq a_{2}$, then equilibrium effort is smaller under $\tau_{H}$ than under $\tau_{L}$ for any given bonus-pool contract $(B, \alpha)$. Using that $\alpha=1$ under the optimal contract, at stage 2 , the firm's objective function (6) is given by

$\pi(B)=\frac{2}{c} \ln \left(\frac{B}{c \sigma \sqrt{2 \pi}}\right)-\frac{2 p(1-p)\left(a_{H}-a_{L}\right)^{2} \tau^{2}}{c \sigma^{2}}+2 \tau\left(p a_{H}+(1-p) a_{L}\right)-B$

which yields the optimal bonus pool $B^{*}=\frac{2}{c}$. Inserting into the firm's objective function leads to

$\pi\left(B^{*}\right)=\frac{2}{c}\left[\ln \left(\frac{2}{c^{2} \sigma \sqrt{2 \pi}}\right)-1\right]-\frac{2 p(1-p)\left(a_{H}-a_{L}\right)^{2} \tau^{2}}{c \sigma^{2}}+2 \tau\left(p a_{H}+(1-p) a_{L}\right)$.

\footnotetext{
${ }^{13}$ All the following results continue to hold for a more general production function where effort and technology are complements, $h\left(e_{i}, a_{i}, \tau\right)=(1+k \tau) e_{i}+a_{i} \tau$, as long as this complementarity is not too strong, i.e., the exogenously given constant $k \geq 0$ is sufficiently small.

${ }^{14}$ An exponential function allows for sufficiently steep cost increases to guarantee existence of a pure-strategy equilibrium in the bonus-pool game between the workers. Such cost function has also be used by Tadelis (2002), Kräkel and Sliwka (2004), and Kräkel (2008).
} 
Hence, the firm will prefer $\tau=\tau_{L}$ to $\tau=\tau_{H}$ if and only if

$$
\begin{gathered}
\pi\left(B^{*} ; \tau_{L}\right)>\pi\left(B^{*} ; \tau_{H}\right) \\
\Leftrightarrow \frac{p(1-p)\left(a_{H}-a_{L}\right)^{2}}{c \sigma^{2}}\left(\tau_{H}+\tau_{L}\right)>p a_{H}+(1-p) a_{L} \\
\Leftrightarrow \frac{\operatorname{Var}[a]}{c \sigma^{2}}\left(\tau_{H}+\tau_{L}\right)>E[a]
\end{gathered}
$$

with $\operatorname{Var}[a]$ denoting the variance and $E[a]$ the mean of unknown worker ability from the firm's perspective.

Condition (10) can now be nicely interpreted. The left-hand side characterizes the detrimental incentive effect of a better technology, whereas the right-hand side measures the positive direct impact on expected output. The condition will be satisfied if $c$ and $\sigma^{2}$ are rather small. Intuitively, the firm should adopt the better technology if workers' effort choices are not very responsive to incentives. Then, equilibrium efforts are rather small under either technology and, consequently, the detrimental incentive effect of a technology improvement is negligible. Effort responsiveness is low when the marginal effort cost function $c^{\prime}\left(e_{i}\right)$ is steep and/or the winner of the contest for $B^{*}$ is determined by luck rather than effort, i.e., if the variance of the random variable $\varepsilon_{2}-\varepsilon_{1}$ is large.

Furthermore, condition (10) holds for large values of $a_{H}-a_{L}$, i.e., for a sufficiently high degree of worker heterogeneity. In that case, the negative incentive effect of a more advanced technology is particularly strong (compare (9)). This finding will be reinforced if technology itself has a significant influence on output and, hence, the outcome of worker competition, i.e., if $\tau_{H}+\tau_{L}$ is large. This also means that the firm should not adopt the better technology if output is particularly responsive to ability (i.e., $\frac{\partial h}{\partial a_{i}}=\tau$ is large).

The impact of $p$ on technology choice can be illustrated by a numerical example. Plotting the two profit functions $\pi\left(B^{*} ; \tau_{H}\right)$ (solid graph) and $\pi\left(B^{*} ; \tau_{L}\right)$ (dashed graph) as functions of $p$ (using $\tau_{H}=2, \tau_{L}=1, c=1$, $\sigma=0.2, a_{H}=0.2$ and $\left.a_{L}=0.1\right)$ yields Figure 1 . 


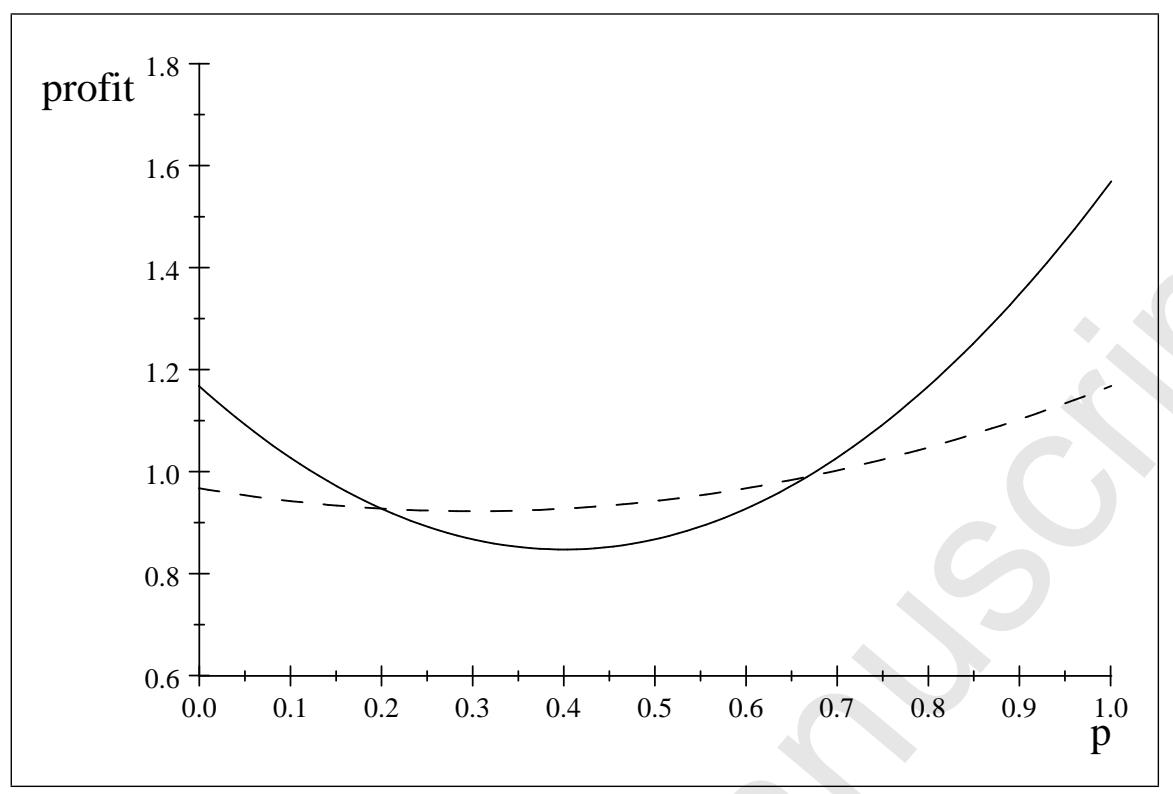

Figure 1: Firm profits as a function of $p$.

If $p$ is rather small or rather large, the firm faces a homogeneous worker match with a very high probability. In that case, the adverse incentive effect due to worker heterogeneity is negligible and the firm prefers the better technology (compare Proposition 3). However, for intermediate values of $p$ the adverse incentive effect becomes crucial so that the firm optimally chooses $\tau_{L}$.

Finally, we can compare the technology choices of a firm in two hypothetical situations $I$ and $I I$ that are characterized by different ability distributions in the labor market. Let $\operatorname{Var}\left[a_{s}\right]=p_{s}\left(1-p_{s}\right)\left(a_{H s}-a_{L s}\right)^{2}$ denote the variance and $E\left[a_{s}\right]=p_{s} a_{H s}+\left(1-p_{s}\right) a_{L s}$ the mean of workers' unknown ability in situation $s(s=I, I I)$ with $E\left[a_{I}\right]>E\left[a_{I I}\right]$. That is, situation $s=I$ offers, on average, a better worker pool than situation $s=I I$. Then, condition (10) states that the firm may prefer the advanced technology only in $s=I I$ but not in situation $s=I$. This is the case if $\operatorname{Var}\left[a_{I}\right]-\operatorname{Var}\left[a_{I I}\right]$ is sufficiently large. In other words, although ability and technology are complements, an improved labor market (in terms of worker ability) may not foster the adoption of better technologies if the improvement is accompanied by higher talent uncertainty. 


\section{Risk-Averse Workers}

In this section, we extend our analysis to the case of risk-averse workers. We now assume that each worker has the utility function

$$
U\left(e_{i}\right)=u\left(I_{i}\right)-c\left(e_{i}\right)
$$

where $u(\cdot)$ is monotonically increasing and concave with $u(0)=0 . I_{i}$ denotes worker $i$ 's monetary income, which consists of his share in the bonus pool in our context. Furthermore, $c(\cdot)$ has the same properties as the cost-of-effort function in Section 2 and each worker's reservation utility is still normalized to zero. Our aim is to show that, if workers are risk averse, the adverse incentive effect of a superior technology may also prevent the adoption of this technology. From Proposition 1 we know that an adverse incentive effect of technology adoption is, in particular, present if effort and technology are independent and if technology and ability are complements. Hence, to simplify our analysis, we focus on production function (8), which exhibits these characteristics. In what follows, we will consider both limited and unlimited liability of workers.

In analogy to the analysis of Section 3, the two workers maximize their respective expected utilities

$u((1-\alpha) B)+[u(\alpha B)-u((1-\alpha) B)] G\left(h\left(e_{1}, a_{1}, \tau\right)-h\left(e_{2}, a_{2}, \tau\right)\right)-c\left(e_{1}\right)$ and $u((1-\alpha) B)+[u(\alpha B)-u((1-\alpha) B)]\left[1-G\left(h\left(e_{1}, a_{1}, \tau\right)-h\left(e_{2}, a_{2}, \tau\right)\right)\right]-c\left(e_{2}\right)$.

The two first-order conditions yield

$g\left(h\left(e_{1}^{*}, a_{1}, \tau\right)-h\left(e_{2}^{*}, a_{2}, \tau\right)\right)[u(\alpha B)-u((1-\alpha) B)]=\frac{c^{\prime}\left(e_{1}^{*}\right)}{\frac{\partial h}{\partial e_{1}}\left(e_{1}^{*}, \tau\right)}=\frac{c^{\prime}\left(e_{2}^{*}\right)}{\frac{\partial h}{\partial e_{2}}\left(e_{2}^{*}, \tau\right)}$,

showing that if a pure-strategy equilibrium exists, it must be unique and symmetric, $e^{*}=e_{1}^{*}=e_{2}^{*}$, with

$g\left(h\left(e^{*}, a_{1}, \tau\right)-h\left(e^{*}, a_{2}, \tau\right)\right) \cdot \frac{\partial h}{\partial e_{1}}\left(e^{*}, \tau\right) \cdot[u(\alpha B)-u((1-\alpha) B)]-c^{\prime}\left(e^{*}\right)=0$. 
Under production technology (8), the workers' equilibrium strategy boils down to

$$
e^{*}=H\left([u(\alpha B)-u((1-\alpha) B)] \cdot g\left(\left(a_{1}-a_{2}\right) \tau\right)\right),
$$

where $H(\cdot)$ denotes the inverse function of $c^{\prime}\left(e_{i}\right)$.

At the contract stage, the firm chooses an optimal bonus-pool contract in order to maximize $\mathrm{e}^{15}$

$$
\begin{gathered}
\pi(B)=P_{H} \cdot 2\left[H([u(\alpha B)-u((1-\alpha) B)] g(0))+a_{H} \tau\right]+ \\
P_{L} \cdot 2\left[H([u(\alpha B)-u((1-\alpha) B)] g(0))+a_{L} \tau\right]+ \\
2 P_{H L} \cdot\left[2 H\left([u(\alpha B)-u((1-\alpha) B)] g\left(\left(a_{H}-a_{L}\right) \tau\right)\right)+\left(a_{H}+a_{L}\right) \tau\right]-B
\end{gathered}
$$

subject to the workers' participation constraint

$$
\begin{gathered}
E\left\{[u(\alpha B)-u((1-\alpha) B)]\left[G\left(h\left(e^{*}\left(a_{1}, a_{2}, B, \alpha, \tau\right), a_{1}, \tau\right)-h\left(e^{*}\left(a_{1}, a_{2}, B, \alpha, \tau\right), a_{2}, \tau\right)\right)\right]\right. \\
\left.+u((1-\alpha) B)-c\left(e^{*}\left(a_{1}, a_{2}, B, \alpha, \tau\right)\right)\right\} \geq 0 \\
\Leftrightarrow u((1-\alpha) B)+[u(\alpha B)-u((1-\alpha) B)] \cdot E\left\{G\left(\left(a_{1}-a_{2}\right) \tau\right)\right\} \\
-E\left\{c\left(H\left([u(\alpha B)-u((1-\alpha) B)] \cdot g\left(\left(a_{1}-a_{2}\right) \tau\right)\right)\right)\right\} \geq 0 .
\end{gathered}
$$

First, we analyze the case of limited liability with $\alpha \in[0,1]$. Since $u(0)=0$ and hence $u((1-\alpha) B) \geq 0$, we can apply the same argument as in Section 3, which allows us to ignore the participation constraint. Consequently, again a winner-takes-all contest is optimal for the firm to induce maximal incentives for a given bonus pool. Expected net profits can therefore be written as

$$
\begin{aligned}
\pi(B)= & P_{H} \cdot 2\left[H(u(B) g(0))+a_{H} \tau\right]+P_{L} \cdot 2\left[H(u(B) g(0))+a_{L} \tau\right]+ \\
& 2 P_{H L} \cdot\left[2 H\left(u(B) g\left(\left(a_{H}-a_{L}\right) \tau\right)\right)+\left(a_{H}+a_{L}\right) \tau\right]-B .
\end{aligned}
$$

Let $B^{*}(\tau)$ denote the optimal size of the bonus pool. Then, applying the envelope theorem at the first stage of the game, where the firm chooses

\footnotetext{
${ }^{15}$ Again, we neglect $2 E[\varepsilon]+2 E[\eta]$, because both terms are irrelevant for the firm's contract-design problem. Furthermore, recall that $g(x)=g(-x)$ due to symmetry.
} 
technology, yields

$$
\begin{gathered}
\frac{\partial \pi\left(B^{*}(\tau), \tau\right)}{\partial \tau}=2\left(p a_{H}+(1-p) a_{L}\right)+ \\
4 P_{H L} H^{\prime}\left(u\left(B^{*}\right) g\left(\left(a_{H}-a_{L}\right) \tau\right)\right) u\left(B^{*}\right) g^{\prime}\left(\left(a_{H}-a_{L}\right) \tau\right)\left(a_{H}-a_{L}\right) .
\end{gathered}
$$

The first expression on the right-hand side of (12) is positive and measures the direct effect of a better technology on expected firm output. The second expression is negative since $g^{\prime}\left(\left(a_{H}-a_{L}\right) \tau\right)<0$ due to $g(\cdot)$ 's single peakedness, indicating the detrimental incentive effect. The firm prefers the less productive technology if the first effect is dominated by the latter one. Thus, the reasoning is quite similar to our argumentation in the case of risk-neutral workers based on condition (7).

If workers are of unlimited liability, payments to workers can be negative so that we can drop the restriction $\alpha \in[0,1]$. Consequently, we cannot ignore the participation constraint any longer. To simplify notation, we define $\underline{u}:=u((1-\alpha) B) \Leftrightarrow(1-\alpha) B=v(\underline{u})$ and $\bar{u}:=u(\alpha B) \Leftrightarrow \alpha B=v(\bar{u})$ with $v:=u^{-1}$ being monotonically increasing and strictly convex. Thus, $B=v(\bar{u})+v(\underline{u})$. Using (11) and the new definitions, the firm's contractdesign problem can be rewritten as follows:

$$
\begin{gathered}
\max _{\bar{u}, \underline{u}} \pi(\bar{u}, \underline{u})=\max _{\bar{u}, \underline{u}} 2\left(P_{H}+P_{L}\right) H([\bar{u}-\underline{u}] g(0)) \\
+4 P_{H L} H\left([\bar{u}-\underline{u}] g\left(\left(a_{H}-a_{L}\right) \tau\right)\right) \\
+2 \tau\left(p a_{H}+(1-p) a_{L}\right)-v(\bar{u})-v(\underline{u})
\end{gathered}
$$

subject to ${ }^{16}$

$$
\begin{aligned}
\underline{u}+[\bar{u}-\underline{u}] E\left\{G\left(\left(a_{1}-a_{2}\right) \tau\right)\right\}-E\left\{c\left(H\left([\bar{u}-\underline{u}] g\left(\left(a_{1}-a_{2}\right) \tau\right)\right)\right)\right\} \geq 0 \\
\Leftrightarrow \frac{1}{2}[\bar{u}+\underline{u}]-\left(P_{H}+P_{L}\right) c(H([\bar{u}-\underline{u}] g(0))) \\
-2 P_{H L} c\left(H\left([\bar{u}-\underline{u}] g\left(\left(a_{H}-a_{L}\right) \tau\right)\right)\right) \geq 0 .
\end{aligned}
$$

\footnotetext{
${ }^{16}$ Note that $E\left\{G\left(\left(a_{1}-a_{2}\right) \tau\right)\right\}=P_{H} G\left(\left(a_{H}-a_{H}\right) \tau\right)+P_{L} G\left(\left(a_{L}-a_{L}\right) \tau\right)+$ $P_{H L} G\left(\left(a_{H}-a_{L}\right) \tau\right)+P_{H L} G\left(\left(a_{L}-a_{H}\right) \tau\right)=\frac{1}{2}$ due to the symmetry of $g(\cdot)$.
} 
Let $\left(\bar{u}^{*}, \underline{u}^{*}\right)=\left(\bar{u}^{*}(\tau), \underline{u}^{*}(\tau)\right)$ denote the solution to the contract-design problem, leading to profits $\pi^{*}=\pi\left(\bar{u}^{*}, \underline{u}^{*}\right)$.

At the first stage, the Lagrangian to the firm's problem with solution $\left(\bar{u}^{*}, \underline{u}^{*}\right)$ reads as

$$
\begin{gathered}
L\left(\bar{u}^{*}, \underline{u}^{*}, \tau\right)=\pi\left(\bar{u}^{*}, \underline{u}^{*}\right)+\lambda\left\{\frac{1}{2}\left(\bar{u}^{*}+\underline{u}^{*}\right)-\left(P_{H}+P_{L}\right) c\left(H\left(\left[\bar{u}^{*}-\underline{u}^{*}\right] g(0)\right)\right)\right. \\
\left.-2 P_{H L} c\left(H\left(\left[\bar{u}^{*}-\underline{u}^{*}\right] g\left(\left(a_{H}-a_{L}\right) \tau\right)\right)\right)\right\}
\end{gathered}
$$

with $\lambda \geq 0$ as the Lagrange multiplier for the participation constraint. Clearly, the participation constraint is binding at the optimum. Otherwise, the firm could decrease $B$ and, at the same time, appropriately increase $\alpha$ so that $\bar{u}-\underline{u}=u(\alpha B)-u((1-\alpha) B)$ remains constant. In other words, by reducing the size of the bonus pool and increasing the share of the better performing worker the firm could reduce its labor costs while holding incentives constant. The firm would proceed in this way and reduce $u((1-\alpha) B)$ until the participation constraint becomes binding. Thus, in general, we have $\lambda>0$. Furthermore, in the optimum, $\underline{u}$ is negative and hence $\alpha>1 .^{17}$

In order to analyze the impact of technology choice on optimal firm profits $\pi^{*}$, we have to apply the envelope theorem to the Lagrangian $L\left(\bar{u}^{*}, \underline{u}^{*}, \tau\right)$ :

$$
\begin{gathered}
\frac{\partial \pi^{*}}{\partial \tau}=\frac{\partial L\left(\bar{u}^{*}, \underline{u}^{*}, \tau\right)}{\partial \tau}=2\left(p a_{H}+(1-p) a_{L}\right)+4 D+ \\
2 D \cdot \lambda c^{\prime}\left(H\left(\left[\bar{u}^{*}-\underline{u}^{*}\right] g(\Delta a \tau)\right)\right) .
\end{gathered}
$$

Here, we define $\Delta a:=a_{H}-a_{L}$ and $D:=p(1-p) H^{\prime}\left(\left[\bar{u}^{*}-\underline{u}^{*}\right] g(\Delta a \tau)\right)\left[\bar{u}^{*}-\right.$ $\left.\underline{u}^{*}\right] g^{\prime}(\Delta a \tau) \Delta a<0$. A comparison of (12) and (13) shows that, under unlimited liability, the direct productivity effect on output and the detrimental incentive effect work again into opposite directions (first line of (13)). However, now we have an additional positive effect (second line of (13)) that mitigates the adverse incentive effect compared to the case of limited liability. This additional effect makes the introduction of a better technology more likely under unlimited than under limited liability. When a better technology

\footnotetext{
${ }^{17}$ Note that under $\underline{u} \geq 0$ each worker would receive a strictly positive rent because of his zero reservation utility.
} 
reduces equilibrium effort due to more uneven worker competition, the workers' effort costs also decrease. Under unlimited liability, the firm gains from this reduction in effort costs: It can lower each worker's expected utility from bonus payments by the same amount, making the participation constraint again just binding. At the same time, incentives can be held constant, i.e., a lower $B$ is accompanied by a larger $\alpha$. By contrast, under limited liability, the firm does not benefit from reduced effort costs because it cannot lower workers' expected utility from bonus payments without further decreasing incentives ( $\alpha$ cannot be larger than 1$)$.

\section{Conclusion}

The previous analysis has shown that a firm that uses relative performance pay to provide its workforce with effort incentives may refrain from implementing an advanced production technology, even if the adoption of this technology is free. A necessary condition for the firm to prefer an inferior technology is that a worker's ability and the production technology are complementary, i.e., a better technology raises the productivity of more able workers more strongly. Then, under an enhanced technology, competition among heterogeneous workers becomes more uneven. As a consequence, workers are discouraged from exerting effort. If this adverse incentive effect is sufficiently strong, it outweighs the advantageous effect of an increased productivity under the new technology.

This main result leads to several empirical predictions. First, the adverse incentive effect is the stronger the more responsive the workers' effort choice is to incentives. In particular, this means that firms which are able to assess workers' performances quite precisely (i.e., $\sigma^{2}$ is low) are less inclined to adopt a superior production technology than firms with a less accurate monitoring technology. Thus, production and monitoring technologies are substitutes.

Second, higher talent uncertainty among workers exacerbates the adverse incentive effect of a new technology. Presuming that talent uncertainty decreases as workers stay longer with the firm and are promoted along the firm's hierarchy, our analysis suggests that a firm benefits more from introducing 
new technologies on higher layers. Thus, taking into account costs for technology adoption, new technologies (e.g., computer systems) should first be implemented on higher hierarchy levels, while adoption on lower levels takes place as technology costs decrease.

Third, we have focused on a situation where the firm can only use relative performance pay due to a lack of cardinal and verifiable performance signals and because relational contracts are not feasible. However, in practice, the firm may prefer relative performance pay even if individual incentive schemes (e.g., piece rates) are, in principle, available. Important reasons may be the elimination of common shocks (see the random variable $\eta$ above) or lower measurement costs. Our analysis implies that, given the feasibility of different forms of incentive contracts, a firm may want to revise its incentive scheme after the adoption of a new production technology. For example, before the availability of a new production technology, the firm might prefer relative performance pay to individual incentive contracts because the former exhibits lower costs for measuring employee performance. However, after technology adoption, it might be worthwhile for the firm to invest in a monitoring technology that allows it to apply individual performance pay. Then, the firm avoids the adverse incentive effect that would occur under a relative incentive scheme. In general, our analysis identifies a new comparative advantage of individual incentive pay if (i) worker ability and the production technology are complements and (ii) the adoption of advanced technologies is crucial for firm success.

Fourth, our paper points out that the problem of not adopting a more productive technology under relative performance pay is less severe if workers are unlimitedly liable. The reason is that, in this case, the firm can lower the total wage sum when effort incentives are diminished. Hence, labormarket regulations that imply positive worker rents (e.g., minimum wages) may impede the fast diffusion of a new technology in industry compared to a situation where workers receive compensation equal to their outside options.

Finally, one may wonder whether welfare could strictly increase if a welfare-maximizing third party and not the firm chooses the production tech- 
nology in stage $1 .^{18}$ In general, adoption of the more productive technology should become more likely in this situation since the third party trades off the adverse incentive effect against all positive technology effects - including the impact on worker rents. In particular, there are cases where a third party has a strong interest in introducing the better technology: Gürtler and Kräkel (2010) show that under limited liability a firm sometimes prefers to implement more than first-best effort in order to exploit worker competition to reduce rents. In such a situation, the firm may forego the better technology to retain incentives. By contrast, the third party may adopt the superior technology to improve productivity and, at the same time, lower effort towards the efficient level.

\section{References}

Amegashie, J.A., Runkel, M., 2007. Sabotaging potential rivals. Social Choice and Welfare 28, 143-162.

Applegate, L., Cash, J., Mills, D.Q., 1988. Information technology and tomorrow's manager. Harvard Business Review, November-December, $128-136$.

Baker, G.P., Gibbons, R., Murphy, K.J., 2002. Relational contracts and the theory of the firm. Quarterly Journal of Economics 117, 39-84.

Baker, G.P., Gibbs, M., Holmström, B., 1994. The internal economics of the firm: Evidence from personnel data. Quarterly Journal of Economics 109, 881-919.

Berndt, E.R., Morrison, C.J., Rosenblum, L.S., 1992. High-tech capital formation and labor composition in U.S. manufacturing industries: An exploratory analysis. Working Paper no. 4010, March (NBER, Cambridge, MA).

\footnotetext{
${ }^{18}$ We thank an anonymous referee for suggesting this question.
} 
Bresnahan, T.F., Brynjolfsson, E., Hitt, L.M., 2002. Information technology, workplace organization, and the demand for skilled labor: Firmlevel evidence. Quarterly Journal of Economics 117, 339-376.

Budde, J., 2007. Bonus pools, limited liability, and tournaments. Governance and the Efficiency of Economic Systems (GESY) Discussion Paper No. 205.

Bull, C., 1987. The existence of self-enforcing implicit contracts. Quarterly Journal of Economics 102, 147-159.

Chen, K.-P., 2003. Sabotage in promotion tournaments. Journal of Law, Economics and Organization 19, 119-140.

Chen, Z., 2006. Fighting collusion in tournaments. MPRA Paper No. 872.

Demougin, D., Fluet, C., 2001. Monitoring versus incentives. European Economic Review 45, 1741-1764.

Demougin, D., Garvie, D., 1991. Contractual design with correlated information under limited liability. RAND Journal of Economics 22, 477-487.

Dixit, A., 1987. Strategic behavior in contests. American Economic Review $77,891-898$.

Drago, R., Garvey, G.T., Turnbull, G.K., 1996. A collective tournament. Economics Letters 50, 223-227.

Endo, K., 1994. Satei (personal assessment) and interworker competition in Japanese firms. Industrial Relations 33, 70-82.

Green, J.R., Stokey, N.L., 1983. A comparison of tournaments and contracts. Journal of Political Economy 91, 349-364.

Gürtler, O., 2008. On sabotage in collective tournaments. Journal of Mathematical Economics 44, 383-393. 
Gürtler, O., Kräkel, M., 2010. Optimal tournament contracts for heterogeneous workers. Journal of Economic Behavior and Organization 75, 180-191.

Hitt, L.M., Snir, E.M., 1999. The role of information technology in modern production: Complement or substitute to other inputs? Wharton School, Discussion Paper.

Hvide, H., 2002. Tournament rewards and risk taking. Journal of Labor Economics 20, 877-898.

Ichniowski, C., Shaw, K., Prennushi, G., 1997. The effects of human resource management practices on productivity: A study of steel finishing lines. American Economic Review 87, 291-313.

Ishiguro, S., 2004. Collusion and discrimination in organizations. Journal of Economic Theory 116, 357-369.

Kalra, A., Shi, M., 2001. Designing optimal sales contests: A theoretical perspective. Marketing Science 20, 170-193.

Kanemoto, Y., MacLeod, W.B., 1992. Firm reputation and self-enforcing labor contracts. Journal of the Japanese and International Economies 6, 144-162.

Konrad, K.A., 2000. Sabotage in rent-seeking contests. Journal of Law, Economics and Organization 16, 155-165.

Kräkel, M., 2008. Optimal risk taking in an uneven tournament game with risk averse players. Journal of Mathematical Economics 44, 1219-1231.

Kräkel, M., Schöttner, A., 2010. Technology choice and incentives under relative performance schemes. Bonn ECON Papers No. 10/2010.

Kräkel, M., Sliwka, D., 2004. Risk taking in asymmetric tournaments. German Economic Review 5, 103-116. 
Laffont, J.-J., Martimort, D., 2002. The theory of incentives. Princeton: Princeton University Press.

Lazear, E.P., 1989. Pay equality and industrial politics. Journal of Political Economy 97, 561-580.

Lazear, E.P., Rosen, S., 1981. Rank-order tournaments as optimum labor contracts. Journal of Political Economy 89, 841-864.

Lim, N., Ahearne, M.J., Ham, S.H., 2009. Designing sales contests: Does the prize structure matter? Journal of Marketing Research 46, 356-371.

Lindbeck, A., Snower, D.J., 2000. Multitask learning and the reorganization of work: From tayloristic to holistic organization. Journal of Labor Economics 18, 353-376.

Malcomson, J.M., 1984. Work incentives, hierarchy, and internal labor markets. Journal of Political Economy 92, 486-507.

Malcomson, J.M., 1986. Rank-order contracts for a principal with many agents. Review of Economic Studies 53, 807-817.

Münster, J., 2007. Selection tournaments, sabotage, and participation. Journal of Economics and Management Strategy 16, 943-970.

Murphy, K.J., 1992. Performance measurement and appraisal: Motivating managers to identify and reward performance. In: Bruns, W.J. Jr. (Ed.). Performance Measurement, Evaluation, and Incentives. Harvard Business School Press, Boston, 37-62.

Murphy, W.H., Dacin, P.A., Ford, N.M., 2004. Sales sontest effectiveness: An examination of sales contest design preferences of field sales forces. Journal of the Academy of Marketing Science 32, 127-143.

Nalebuff, B.J., Stiglitz, J.E., 1983. Prizes and incentives: Towards a general theory of compensation and competition. Bell Journal of Economics 3, 21-43. 
O'Keeffe, M., Viscusi, W.K., Zeckhauser, R.J., 1984. Economic contests: Comparative reward schemes. Journal of Labor Economics 2, 27-56.

Rajan, M.V., Reichelstein, S., 2006. Subjective performance indicators and discretionary bonus pools. Journal of Accounting Research 44, 585-618.

Rajan, M.V., Reichelstein, S., 2009. Objective versus subjective indicators of managerial performance. Accounting Review 84, 209-237.

Schotter, A., Weigelt, K., 1992. Asymmetric tournaments, equal opportunity laws, and affirmative action: Some experimental results. Quarterly Journal of Economics 107, 511-539.

Sutter, M., Strassmair, C., 2009. Communication, cooperation and collusion in team tournaments - an experimental study. Games and Economic Behavior 66, 506-525.

Tadelis, S., 2002. The market for reputations as an incentive mechanism. Journal of Political Economy 110, 854-882.

Thomas, C.W., 2002. The rise and fall of Enron. Journal of Accountancy $193,41-48$.

Treble, J., van Gameren, E., Bridges, S., Barmby, T., 2001. The internal economics of the firm: Further evidence from personnel data. Labour Economics 8, 531-552. 